\title{
Short Communication: Comparison of Bulk Milk, Yield-Corrected, and Average Somatic Cell Counts as Parameters to Summarize the Subclinical Mastitis Situation in a Dairy Herd
}

\author{
J. J. Lievaart, ${ }^{* 1,2}$ W. D. J. Kremer, ${ }^{*}$ and H. W. Barkema† \\ *Department of Farm Animal Health, Faculty of Veterinary Medicine, University of Utrecht, Utrecht, the Netherlands \\ †Department of Production Animal Health, Faculty of Veterinary Medicine, University of Calgary, Calgary, Alberta, Canada
}

\begin{abstract}
In this study, the correlation was determined between the prevalence of high cow-level somatic cell count (SCC $>250,000$ cell $\mathrm{s} / \mathrm{mL}$ ), a summary of the subclinical mastitis situation in a dairy herd, and 3 average herd SCC parameters: bulk milk SCC (BMSCC), yield-corrected test-day SCC (CHSCC), and the arithmetic average test-day SCC (HSCC) of the lactating herd. The herd prevalence of cows with an SCC of $>250,000$ cells $/ \mathrm{mL}$ was calculated by using Dairy Herd Improvement data. Herds were included if BMSCC was sampled within $2 \mathrm{~d}$ of the Dairy Herd Improvement test day and if the BMSCC did not exceed 400,000 cells/mL. The interval between sampling, 0,1 , or $2 \mathrm{~d}$, did not significantly influence the correlation between BMSCC and the prevalence of high SCC. The correlations between the prevalence of high SCC and BMSCC, yield-corrected test-day SCC, and HSCC, examined by using a linear regression model, were $0.64,0.78$, and 0.89 , respectively. Therefore, it can be concluded that, based on the highest correlation, HSCC is a more appropriate parameter than BMSCC to summarize the average herd subclinical mastitis situation in a dairy herd.
\end{abstract}

Key words: udder health, correlation, herd somatic cell count, bulk milk somatic cell count

Bulk milk SCC (BMSCC) is an easily available and frequently used parameter to summarize the subclinical mastitis situation in a dairy herd. Although the percentage of cows with an individual SCC of $>250,000$ cells $/ \mathrm{mL}$ is an excellent parameter to summarize the subclinical mastitis situation, average herd SCC may be another useful complementary parameter. Bulk

\footnotetext{
Received December 21, 2006.

Accepted May 9, 2007.

${ }^{1}$ Corresponding author: jlievaart@csu.edu.au

${ }^{2}$ Charles Sturt University, Wagga Wagga, New South Wales, Australia.
}

milk SCC is mainly used by dairy processors as a quality parameter, but it is also frequently used in research on udder health management and control strategies (e.g., Goodger et al., 1993; Faye et al., 1994; Barkema et al., 1998, 1999; Tadich et al., 2003; De Vliegher et al., 2004). It is questionable, however, whether BMSCC is the most appropriate parameter, because, for a variety of reasons, milk is withheld from the bulk tank. Instead of using BMSCC, another option would be to use individual cow DHI SCC data and determine a yield-corrected test-day SCC (CHSCC) or the arithmetic average test-day SCC of the lactating herd (HSCC). These options were previously mentioned in other studies but have not been validated (Schukken et al., 2003; Bradley and Green, 2005; Valde et al., 2005). It seems logical that parameters calculated by using the SCC of all lactating animals in the herd would more accurately reflect the subclinical mastitis situation in a dairy herd, because the milk of some cows is withheld from the bulk tank. The goal of this study was therefore to determine whether CHSCC or HSCC would be a more appropriate parameter than BMSCC to summarize the subclinical mastitis situation in a dairy herd.

Most of the data used in this study were presented earlier (Barkema et al., 1998). In short, milk-recording and BMSCC data were collected on 300 dairy farms in the northern part of the Netherlands in a study on bulk mastitis and management practices. Mean HSCC of a DHI test day was calculated as the arithmetic mean SCC of all lactating animals. Additionally, a herd SCC corrected for milk yield (CHSCC) was calculated by multiplying the daily test-day milk yield of each cow with its test-day SCC, and averaging this figure over all lactating cows in the herd. The prevalence of high SCC at a test day was defined as the percentage of lactating cows with SCC of $>250,000$ cells/mL. This cutoff value is also used by the Dutch DHI organization in its monthly test results. Bulk milk SCC and milk-recording data were included in the analysis if the BMSCC sample was collected within 2 


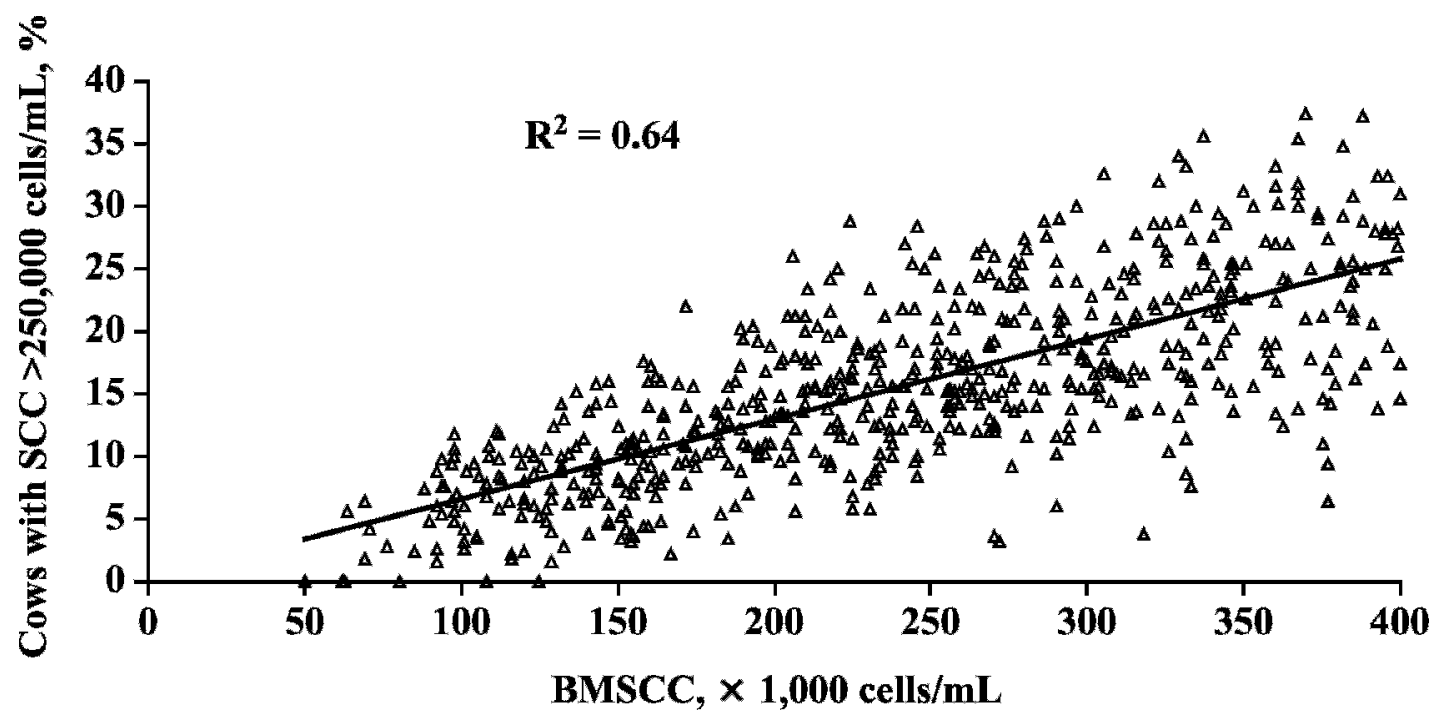

Figure 1. Correlation $\left(\mathrm{R}^{2}\right)$ between bulk milk SCC (BMSCC) and the percentage of cows with a test-day SCC of $>250,000$ cells $/ \mathrm{mL}$.

$\mathrm{d}$ of the individual milk-recording data and if the BMSCC did not exceed 400,000 cells/mL, which is currently used as the penalty limit in the Netherlands. To compare BMSCC, CHSCC, and HSCC in the same range, this cutoff value of 400,000 cells $/ \mathrm{mL}$ was used for all 3 parameters. In total, 786 test days and BMSCC of 246 farms were included in the analyses. The correlations between the percentage of high-SCC cows and the 3 parameters, BMSCC, CHSCC, and HSCC, were examined by using a partial correlation function to correct for the number of data per farm
(SPSS version 12.0, SPSS Inc., Chicago, IL). The heteroskedasticity of the data was corrected by using the weighted variances instead of the normal variances. To determine the effect of the interval between BMSCC sampling and DHI test day, separate models were run for $0-, 1-$, and 2-d intervals. The proportion of variance in the outcome variable that was explained by a dependent variable was calculated as the correlation coefficient, $R^{2}$. To test the difference in $R^{2}$ between the dependent variables, and between the 3 BMSCC models with different intervals with DHI test day, the

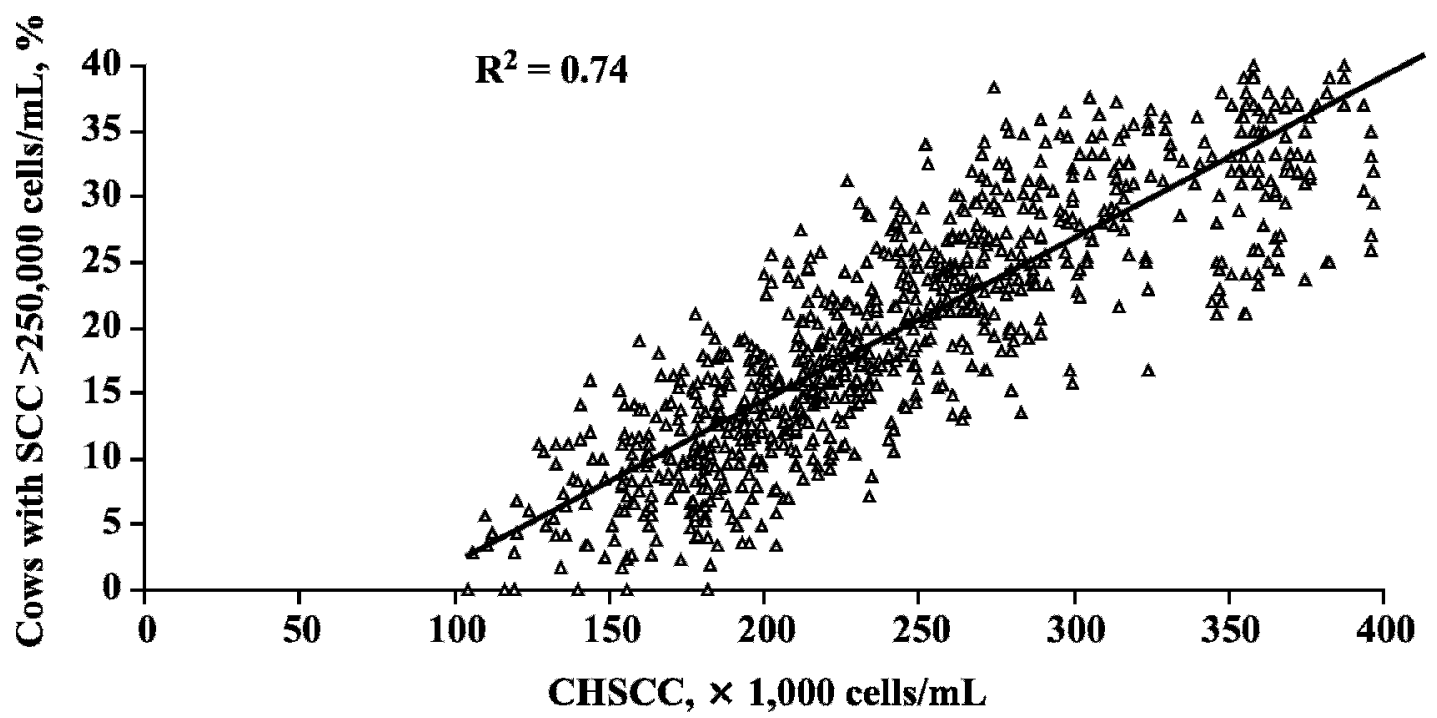

Figure 2. Correlation $\left(\mathrm{R}^{2}\right)$ between yield-corrected SCC (CHSCC) and the percentage of cows with a test-day SCC of $>250,000$ cells $/ \mathrm{mL}$. 


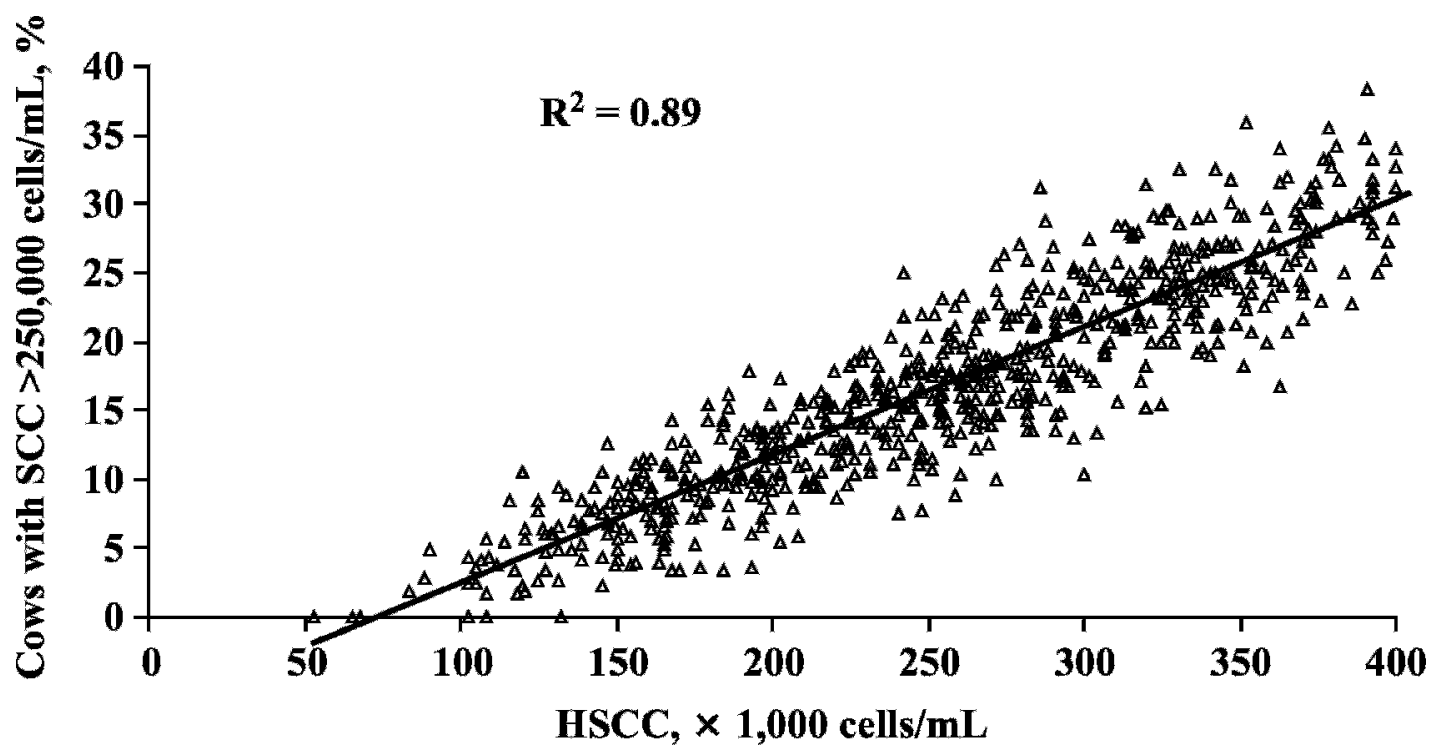

Figure 3. Correlation $\left(\mathrm{R}^{2}\right)$ between the average SCC (HSCC) and the percentage of cows with a test-day SCC of $>250,000$ cells $/ \mathrm{mL}$.

model was also tested by using the statistical program $\mathrm{R}$ (http://www.r-project.org/; version 2.2.0). This program provided an Akaike information criterion (AIC) value for each model that represented the goodness of fit (Akaike, 1973). A model was considered as having a better fit if the AIC value of the model increased by more than the absolute number of 2 compared with another model. The model with the lowest AIC value was considered to be the best linear regression model (Akaike, 1973). Somatic cell counts have a log-normal distribution. Therefore, in most studies of individual and herd-level SCC, a logarithmic transformation is used. In our opinion, this was not necessary in this study because the contribution of individual cows to the bulk tank needed to be calculated.

Bulk milk SCC, CHSCC, and HSCC had $\mathrm{R}^{2}$ with a prevalence of high SCC of 0.64 [95\% confidence interval (CI): 0.63 to $0.65 ; P<0.001$; Figure 1], $0.74(95 \%$ CI: 0.71 to $0.77 ; P<0.001$; Figure 2$)$, and $0.89(95 \%$ CI: 0.87 to $0.91 ; P<0.001$; Figure 3 ), respectively. The models with BMSCC, CHSCC, and HSCC had AIC values of $4,875,4,109$, and 4,035, respectively. The $\mathrm{R}^{2}$ of the prevalence of high SCC and BMSCC with an interval of 0,1 , and $2 \mathrm{~d}$ were 0.62 (95\% CI: 0.60 to $0.64 ; P<0.001$ ), 0.63 (95\% CI: 0.60 to $0.66 ; P<0.001$ ), and 0.61 (95\% CI: 0.58 to $0.64 ; P<0.001$ ), respectively.

We conclude that, based on the highest correlation with the percentage of cows with subclinical mastitis, HSCC is a more appropriate parameter to summarize the subclinical mastitis situation in a dairy herd than the frequently used BMSCC. Therefore, the use of the HSCC parameter is preferable if DHI data are avail- able. The correlation of BMSCC with the prevalence of high SCC is moderate, and there was no difference in the correlation of BMSCC and the percentage of high-SCC cows if the BMSCC sample was collected 0, 1 , or $2 \mathrm{~d}$ after milk recording. Apart from the influence of individual cow milk yield, a possible reason for the merely moderate correlation between BMSCC and the percentage of high-SCC cows is the withholding of milk of high-SCC cows.

\section{ACKNOWLEDGMENT}

We thank the Dutch Royal Herd Service for providing the test-day data.

\section{REFERENCES}

Akaike, H. 1973. Information theory and an extension of the maximum likelihood principle. Pages 267-281 in Second Int. Symp. on Information Theory, Budapest, Hungary. Tsahkadsor, Armenia.

Barkema, H. W., Y. H. Schukken, T. J. G. M. Lam, M. L. Beiboer, G. Benedictus, and A. Brand. 1998. Management practices associated with low, medium, and high somatic cell counts in bulk milk. J. Dairy Sci. 81:1917-1927.

Barkema, H. W., J. D. Van der Ploeg, Y. H. Schukken, T. J. G. M. Lam, G. Benedictus, and A. Brand. 1999. Management style and its association with bulk milk somatic cell count and incidence rate of clinical mastitis. J. Dairy Sci. 82:1655-1663.

Bradley, A., and M. Green. 2005. Use and interpretation of somatic cell count data in dairy cows. In Pract. 27:310-315.

De Vliegher, S., H. Laevens, H. W. Barkema, I. R. Dohoo, H. Stryhn, G. Opsomer, and A. de Kruif. 2004. Management practices and 
heifer characteristics associated with early lactation somatic cell count of Belgian dairy heifers. J. Dairy Sci. 87:937-947.

Faye, B., N. Dorr, F. Lescourret, J. Barnouin, and M. Chassagne. 1994. Farming practices associated with the udder infection complex. Vet. Res. 25:213-218.

Goodger, W. J., T. Farver, J. Pelletier, P. Johnson, G. de Snayer, and J. Galland. 1993. The association of milking management practices with bulk tank somatic cell counts. Prev. Vet. Med. $15: 235-251$.
Schukken, Y. H., D. J. Wilson, F. Welcome, L. Garrison-Tikofsky, and R. N. Gonzalez. 2003. Monitoring udder health and milk quality using somatic cell counts. Vet. Res. 34:579-596.

Tadich, N., J. Kruze, G. Locher, and L. E. Green. 2003. Risk factors associated with BMSCC greater than 200,000 cells/ml in dairy herds in southern Chile. Prev. Vet. Med. 58:15-24.

Valde, J. P., O. Osteras, and E. Simensen. 2005. Description of herd level criteria for good and poor udder health in Norwegian dairy cows. J. Dairy Sci. 88:86-92. 